\title{
Association between calcium-sensing receptor (CaSR) R990G, CaSR A986S, and CaSR Q1011E gene polymorphisms and the risk of urolithiasis: a meta-analysis
}

\author{
Besut Daryanto ${ }^{1} \mathbb{D}$, Basuki Bambang Purnomo ${ }^{1} \mathbb{D}$, Atma Gunawan² ${ }^{\mathbb{D}}$, Fredo Tamara ${ }^{3} \mathbb{D}$, Saga Aditya Hutama ${ }^{4} \mathbb{D}$, \\ Ema Dianita Mayasari ${ }^{3}$ (D) Arum Gladys Kusumaningrum ${ }^{3}$ (D) and Jonny Karunia Fajar ${ }^{3,5^{*}}$ (D)
}

\begin{abstract}
Backgrounds: In the last two decades, studies have been widely carried out to assess the association between singlenucleotide polymorphisms (SNPs) of calcium-sensing receptor (CaSR) gene in exon 7 and the risk of urolithiasis. However, inconsistency across the studies was reported. Therefore, our current study aimed to perform a meta-analysis concerning the association between the risk of urolithiasis and the gene polymorphisms of CaSR R990G, CaSR A986S, and CaSR Q1011E.

Methods: Published papers from PubMed, Embase, Cohcrane, and Web of science were included for the study, and they were analyzed using fixed or random effect model.

Results: A total of 11 papers consisting of eight papers evaluating CaSR R990G, nine papers evaluating CaSR A986S, and five papers evaluating CaSR Q1011E were included in our analysis. Our pooled calculation found that protective effect against urolithiasis was observed in R allele and RR genotype of CaSR R990G and A allele and AA genotype of CaSR A986S. Conversely, increased susceptibility to urolithiasis was found in G allele and RG genotype of CaSR R990G and S allele of CaSR A986S. Interestingly, our findings in sub-group analysis confirmed that the correlation between CaSR R990G and urolithiasis was found in Caucasian population. Meanwhile, in Asian population, the association was observed in CaSR A986S.
\end{abstract}

Conclusions: CaSR R990G and CaSR A986S, but not CaSR Q1011E, are associated with the risk of urolithiasis.

Keywords: Calcium-sensing receptor, CaSR R990G, CaSR A986S, CaSR Q1011E, Urolithiasis, Gene polymorphism

\section{Background}

Urolithiasis was reported as the main health problem and associated with high morbidity in some countries such as Taiwan, Germany, the USA, Greece, Iceland, and Iran [18]. The prevalence of urolithiasis vary, ranging from $1.9 \%$ in the USA to $15 \%$ in Greece [2-8]. Urolithiasis had been reported to cause several fatal complication including hydronephrosis, perinephric abscess [9], and end-stage renal failure [10]. To date, the treatment for urolithiasis remains challenging due to discrepancies regarding the clinical indications and the efficacy [11], and it was

\footnotetext{
* Correspondence: gembyok@gmail.com

${ }^{3}$ Brawijaya Internal Medicine Research Center, Department of Internal

Medicine, Faculty of Medicine, Universitas Brawijaya, Malang 65145, Indonesia

${ }^{5}$ Medical Research Unit, School of Medicine, Universitas Syiah Kuala, Banda

Aceh 23111, Indonesia

Full list of author information is available at the end of the article
}

reported to spend high cost expenditure [12]. This cost expenditure is predicted to increase because the incidence and prevalence of this disease were reported to increase in the last few decades [11]. This phenomenon is considered an economic burden for health systems [12], and therefore we described this condition like "the deer at the edge of the cliff." Hence, to anticipate the worsening of this condition, a comprehensive understanding concerning urolithiasis pathogenesis especially at genetic level is crucial for future treatment and prevention.

In the scope of urolithiasis, calcium stones represent the majority of stone types and comprises about $80 \%$ of all urinary calculi [10]. Although calcium stones are caused by multifactoral, however, the basic pathway is an imbalance of calcium homeostasis [13]. This pathological state is dominantly governed by calcium-sensing 
receptor (CaSR) [14], a dimeric membrane protein belonging to the family of G-protein coupled receptor (GPCR) [15]. The CASR gene contains two promoters and seven exons [16]. However, the expression of CaSR in the context of calcium homeostasis is primarily affected by a high region in CaSR gene, defined as exon 7. During this time, single-nucleotide polymorphisms (SNPs) widely reported in exon 7 of CaSR gene were as follows: a guanine-thymine substitution at codon 986 (A986S; rs1801725), the subtitution of an adenine-guanine at codon 990 (R990G; rs1042636), and a cytosine-guanine substitution at codon 1011 (Q1011E; rs1801726) [17]. To date, the reports concerning those SNPs in patients with urolithiasis were inconclusive. Furthermore, previous metaanalysis [18] in this circumstance did not suffice to establish a potent conclusion because of some limitations.

Our present study aimed to perform a meta-analysis regarding the correlation between the risk of urolithiasis and the gene polymorphisms of CaSR R990G, CaSR A986S, and CaSR Q1011E. Our present study was intended to clarify the inconsistency and to elucidate better correlation between those SNPs and the risk of urolithiasis.

\section{Methods}

\section{Study design}

During the period (February-April 2019), a meta-analysis was carried out to assess the correlation between CaSR gene polymorphisms (CaSR R990G, CaSR A986S, and CaSR Q1011E) and the risk of urolithiasis. To reach this purpose, published papers from PubMed, Embase, Cohcrane, and Web of science were collected for calculation of odd ratio (OR) and $95 \%$ confidence interval $(95 \% \mathrm{CI})$ using either random or fixed effect model. The protocols in our current study including papers selection, data extraction, quality assessment, and statistical analysis were adapted from our previous meta-analyses [19-22], and we also used the checklist of the Preferred Reporting Items for Systematic Review and Meta-analysis (PRISMA) to guide the protocols in our study [23].

\section{Eligibility criteria}

The following criteria were used to include the papers in our study: (1) evaluating the correlation between CaSR gene polymorphisms (CaSR R990G, CaSR A986S, and CaSR Q1011E) and the risk of urolithiasis; and (2) having required data for calculation of OR95\%CI. Furthermore, the exclusion criteria were as follows: (1) unrelated titles and abstracts, (2) reviews and commentaries, (3) incomplete and or ungeneralized data, (4) having deviation from Hardy-Weinberg equilibrium (X2 > 3.84 was defined as deviation from Hardy-Weinberg equilibrium) [24], and (5) double publication.

\section{Search strategy and data extraction}

Papers concerning the association between CaSR gene polymorphisms (CaSR R990G, CaSR A986S, and CaSR Q1011E) and the risk of urolithiasis were searched in major scientific websites (PubMed, Embase, Cochrane, and Web of science) up to 10 April 2019. In searching the articles, we did not restrict the publication language. If we found articles with language that we did not understand, we established a comprehensive consultation with Language Center of Universitas $B^{* * * * * * * *}$ (blinded due to double blind review). Moreover, to perform a comprehensive searching, we used the combination of the following key words: (urolithiasis or nephrolithiasis or kidney stone or renal stone) and (calciumsensing receptor R990G or CaSR R990G) and (calciumsensing receptor A986S or CaSR A986S) and (calcium-sensing receptor Q1011E or CaSR Q1011E). If articles with the same study data were found, only articles with the larger sample size were included in our analysis. For data extraction, the following information were extracted from each study: (1) first author name, (2) publication year, (3) country of origin, (4) genotyping method, (5) sample size of case and control, and (6) genotype frequencies of urolithiasis and control groups. To provide data with high validity and to prevent errors in data extraction, the extraction was conducted by three independent authors (JKF, AG, FT).

\section{Assessment of the methodology quality}

To assess the quality of each paper, we used NewcastleOttawa Scale (NOS) [25]. This evaluation was conducted by three independent authors (JKF, AG, FT). The evaluation consisted of three factors such as study selection (four points), the comparability of the groups (two points), and the ascertainment of the exposure (three points). In this evaluation, each paper had the score ranging from 0 (the worst) to 9 (the best). The quality was interpreted as good (score $\geq 7$ ), moderate (score 5-6), and poor (score $\leq$ 4). If the discrepancy between the three independent authors was found, we established a consensus.

\section{Covariates and sub-group analysis}

To provide a comprehensive analysis, all alleles and genotypes models were evaluated to assess the correlation and effect estimates. For CaSR R990G, the genetic models were R vs. G; G vs. R; RR vs. RG + GG; RG vs. RR + GG; and GG vs. RR + RG. For CaSR A986S, the genetic models were A vs. S; S vs. A; AA vs. AS + SS; $\mathrm{AS}$ vs. AA + SS; and SS vs. AA + AS. Moreover, for CaSR Q1011E, the genetic models were Q vs. E; E vs. Q; QQ vs. QE + EE; QE vs. QQ + EE; and EE vs. QQ + QE. Moreover, we also performed sub-group analysis of all genetic models according to ethnicity sub-group (Asian and Caucasian). 


\section{Statistical analysis}

The calculation of pooled OR and 95\%CI, determined by $Z$ test, was used to assess the association between CaSR gene polymorphisms and the risk of urolithiasis. The effect model for determining the correlation, whether using fixed or random effect model, was assessed using a $Q$ test. A fixed effect model was used if we found no heterogeneity. Conversely, random effect model was used if the evidence of heterogeneity $(p<0.10)$ was observed. Moreover, an Egger's test was employed to assess potential of publication bias. To prevent analysis errors, the analysis in our present study was performed using two different software (comprehensive meta-analysis [CMA, New Jersey, USA] version 2.1 and Review Manager [Revman Cochrane, London, UK] version 5.3) and three independent authors (JKF, AG, FT). If we found discrepancy, we conducted a consensus to discuss the discrepancy between authors.

\section{Results and discussion}

\section{Eligible studies}

Our final searching strategy identified 11 papers compatible for meta-analysis. Of them, we found eight studies evaluating CaSR R990G; nine studies evaluating CaSR A986S; and five studies evaluating CaSR Q1011E. This number of papers were retrieved from searching in PubMed, Embase, Cochrane, and Web of science; and we selected the papers in accordance with eligibility criteria. In the initial searching, we identified 338 papers. Of those, 312 papers were excluded because of irrelevant title and or abstract. Moreover, 15 papers were also excluded because of review (nine), not providing required data for calculation of OR and 95\%CI (four), and having deviation from Hardy-Weinberg equilibrium (two). Figure 1 demonstrates a flowchart concerning eligibility pathway in our meta-analysis. For quality assessment, all papers included in our analysis had moderate (NOS score 5-6) or high-quality (NOS score $\geq 7$ ). Baseline characteristics of studies included in our meta-analysis are summarized in Table 1 for CaSR R990G, Table 2 for CaSR A986S, and Table 3 for CaSR Q1011E.

\section{Data synthesis}

A total of eight studies about CaSR R990G consisting of 1853 cases and 1514 controls were enrolled for our analysis. On the whole analysis, our findings revealed that decreased risk of urolithiasis was observed in $\mathrm{R}$ allele (OR95\%CI = 0.69 [0.51-0.95], $p=0.0240$ ) and RR genotype (OR95\%CI $=0.60[0.41-0.89], p=0.0120)$. On the contrary, increased

Potential papers were identified through PubMed, Embase, Cochrane, and Web of science up to 10 April $2019(n=338)$

Papers were excluded because of irrelevance after reading the titles and or abstracts $(n=312)$

Potential relevant papers were included for further review in full text $(n=26)$

1. Papers were excluded because of reviews or comments $(n=$ 9)

2. Papers were excluded because of not providing sufficient data for calculation of $O R$ and $95 \% \mathrm{CI}(n=4)$

3. Papers were excluded because of Hardy-Weinberg deviation $(n=2)$

11 studies were included in the meta-analysis (R990G

$=8 ; \mathrm{A} 986 \mathrm{~S}=9 ; \mathrm{Q1011E}=5$ )

Fig. 1 A flowchart of eligibility pathway in our study 
Table 1 Baseline characteristics of studies concerning CaSR R990G gene polymorphism in patients with urolithiasis included in the meta-analysis

\begin{tabular}{|c|c|c|c|c|c|c|c|c|c|c|c|c|c|}
\hline \multirow[t]{2}{*}{ Author and year } & \multicolumn{4}{|c|}{ Case } & \multicolumn{4}{|c|}{ Control } & \multirow[t]{2}{*}{ Ethnicity } & \multirow[t]{2}{*}{ Type of stone } & \multirow[t]{2}{*}{ Genotyping } & \multirow{2}{*}{$\begin{array}{l}X^{2} \\
H W E\end{array}$} & \multirow{2}{*}{$\begin{array}{l}\text { NOS } \\
{[S / C / E]}\end{array}$} \\
\hline & $\mathrm{RR}$ & RG & GG & $\mathrm{N}$ & $\mathrm{RR}$ & RG & GG & $\mathrm{N}$ & & & & & \\
\hline Ding et al. 2017 [26] & 109 & 348 & 158 & 615 & 76 & 172 & 67 & 315 & Asian & Calcium oxalate & PCR & 2.72 & $6[3 / 1 / 2]$ \\
\hline Hamilton et al. 2009 [30] & 51 & 5 & 0 & 56 & 180 & 11 & 0 & 191 & Caucasian & Calcium oxalate & PCR-RFLP & 0.17 & $7[3 / 2 / 2]$ \\
\hline Han et al. 2013 [31] & 20 & 40 & 10 & 70 & 24 & 53 & 17 & 94 & Asian & Calcium oxalate & $P C R$ & 1.69 & $6[3 / 1 / 2]$ \\
\hline Li et al. 2018 [32] & 191 & 301 & 132 & 624 & 152 & 217 & 101 & 470 & Asian & Calcium oxalate & PCR & 2.02 & $8[4 / 2 / 2]$ \\
\hline Peretokina et al. 2015 [33] & 84 & 23 & 3 & 110 & 60 & 15 & 2 & 77 & Caucasian & Calcium oxalate and phosphate & PCR & 0.76 & $6[3 / 1 / 2]$ \\
\hline Shakhssalim et al. 2010 [27] & 87 & 10 & 2 & 99 & 105 & 2 & 0 & 107 & Asian & Calcium oxalate & PCR & 0.01 & $7[4 / 1 / 2]$ \\
\hline Vezzoli et al. 2007 [28] & 105 & 17 & 2 & 124 & 115 & 4 & 0 & 119 & Caucasian & Calcium oxalate & $P C R$ & 0.03 & $6[3 / 1 / 2]$ \\
\hline Vezzoli et al. 2014 [29] & 133 & 22 & 0 & 155 & 136 & 5 & 0 & 141 & Caucasian & Calcium oxalate & PCR & 0.05 & $6[3 / 1 / 2]$ \\
\hline
\end{tabular}

CaSR calcium-sensing receptor, $P C R$ polymerase chain reaction, $P C R$-RFLP PCR-restriction fragment length polymorphism, HWE Hardy-Weinberg equilibrium, NOS Newcastle-Ottawa Scale, $S$ selection, $C$ comparability, E exposure

risk of urolithiasis was found in $\mathrm{G}$ allele $(\mathrm{OR} 95 \% \mathrm{CI}=1.44$ [1.05-1.98], $p=0.0240)$ and RG genotype $(\mathrm{OR} 95 \% \mathrm{CI}=$ 1.48 [1.05-2.09], $p=0.0260$ ) (Fig. 2a, b). Moreover, we failed to show the correlation in GG genotype. In subgroup analysis, our calculation found that the association was observed only in Caucasian sub-group. $\mathrm{R}$ allele (OR95\%CI $=0.43[0.19-0.96], p=0.0400)$ and RR genotype $(\mathrm{OR} 95 \% \mathrm{CI}=0.42[0.19-0.93], p=0.0330)$ were associated with decreased risk of urolithiasis. Conversely, G allele $(\mathrm{OR} 95 \% \mathrm{CI}=2.35$ [1.03-5.37], $p=0.0400)$ and RG genotype (OR95\%CI $=2.32[1.08-5.00], p=0.0310)$ were associated with increased risk of urolithiasis (Fig. 2c, d). The summary of correlation between urolithiasis and CaSR gene polymorphism is presented in Table 4.

Totally, 2402 cases and 2066 controls retrieved from nine studies concerning CaSR A986S were included in our analysis. Our overall analysis found that A allele $(\mathrm{OR} 95 \% \mathrm{CI}=0.64[0.49-0.84], p=0.0010)$ and AA genotype $(\mathrm{OR} 95 \% \mathrm{CI}=0.66[0.48-0.91], p=0.0110)$ were associated with decreased risk of urolithiasis. Conversely, increased risk of urolithiasis was observed in $\mathrm{S}$ allele
(OR95\%CI $=1.56$ [1.19-2.04], $p=0.0010)$ (Fig .3a). We failed to confirm the correlation in AS and SS genotype. In sub-group analysis, our findings confirmed that the correlation was found in Asian population. The decreased risk of urolithiasis was found in A allele $(\mathrm{OR} 95 \% \mathrm{CI}=0.55$ [0.44-0.70], $p<0.0001)$ and AA genotype (OR95\%CI = 0.56 [0.38-0.82], $p=0.0030)$. On other hands, increased risk of urolithiasis was observed in $\mathrm{S}$ allele $(\mathrm{OR} 95 \% \mathrm{CI}=$ 1.81 [1.43-2.29], $p<0.0001)$ and AS genotype (OR95\%CI $=1.71$ [1.16-2.53], $p=0.0070$ ) (Fig. 3b, c). We summarize the correlation between CaSR A986S gene polymorphism and the risk of urolithiasis in Table 5.

For the association between CaSR Q1011E gene polymorphism and the risk of urolithiasis, we collected five papers consisting of 1127 cases and 991 controls. Overall, our cumulative calculation found no significant association between the risk of urolithiasis and all genetic models of CaSR Q1011E. Moreover, in sub-group analysis, we also failed to clarify the association between the risk of urolithiasis and all genetic models of CaSR Q1011E gene polymorphism. Summary of the relation

Table 2 Baseline characteristics of studies concerning CaSR A986S gene polymorphism in patients with urolithiasis included in the meta-analysis

\begin{tabular}{|c|c|c|c|c|c|c|c|c|c|c|c|c|c|}
\hline \multirow[t]{2}{*}{ Author and year } & \multicolumn{4}{|c|}{ Case } & \multicolumn{4}{|c|}{ Control } & \multirow[t]{2}{*}{ Ethnicity } & \multirow[t]{2}{*}{ Type of stone } & \multirow[t]{2}{*}{ Genotyping } & \multirow{2}{*}{$\begin{array}{l}X^{2} \\
\text { HWE }\end{array}$} & \multirow{2}{*}{$\begin{array}{l}\text { NOS [S/ } \\
\text { C/E] }\end{array}$} \\
\hline & $\overline{\mathrm{AA}}$ & AS & SS & $\mathrm{N}$ & $\overline{A A}$ & AS & SS & $\mathrm{N}$ & & & & & \\
\hline Corbetta et al. 2006 [39] & 58 & 28 & 8 & 94 & 91 & 42 & 4 & 137 & Caucasian & Calcium oxalate & PCR & 0.10 & $6[3 / 1 / 2]$ \\
\hline Ding et al. 2017 [26] & 589 & 25 & 1 & 615 & 303 & 12 & 0 & 315 & Asian & Calcium oxalate & $P C R$ & 0.12 & $6[3 / 1 / 2]$ \\
\hline Guha et al. 2015 [38] & 116 & 82 & 2 & 200 & 162 & 37 & 1 & 200 & Asian & Calcium oxalate & PCR & 0.52 & $7[3 / 2 / 2]$ \\
\hline Hamilton et al. 2009 [30] & 110 & 33 & 14 & 157 & 372 & 91 & 6 & 469 & Caucasian & Calcium oxalate & PCR-RFLP & 0.03 & $7[3 / 2 / 2]$ \\
\hline Han et al. 2013 [31] & 64 & 5 & 1 & 70 & 88 & 6 & 0 & 94 & Asian & Calcium oxalate & $P C R$ & 0.10 & $6[3 / 1 / 2]$ \\
\hline Kim et al. 2011 [40] & 415 & 18 & 0 & 433 & 191 & 6 & 0 & 197 & Asian & Calcium oxalate and citrate & PCR-RFLP & 0.05 & $7[3 / 2 / 2]$ \\
\hline Li et al. 2018 [32] & 561 & 62 & 1 & 624 & 435 & 35 & 0 & 470 & Asian & Calcium oxalate & PCR & 0.70 & $8[4 / 2 / 2]$ \\
\hline Peretokina et al. 2015 [33] & 78 & 26 & 6 & 110 & 48 & 25 & 4 & 77 & Caucasian & Calcium phosphate & $P C R$ & 0.10 & $6[3 / 1 / 2]$ \\
\hline Shakhssalim et al. 2010 [27] & 71 & 26 & 2 & 99 & 93 & 14 & 0 & 107 & Asian & Calcium oxalate & PCR & 0.52 & $7[4 / 1 / 2]$ \\
\hline
\end{tabular}


Table 3 Baseline characteristics of studies concerning CaSR Q1011E gene polymorphism in patients with urolithiasis included in the meta-analysis

\begin{tabular}{|c|c|c|c|c|c|c|c|c|c|c|c|c|c|}
\hline \multirow[t]{2}{*}{ Author and year } & \multicolumn{4}{|c|}{ Case } & \multicolumn{4}{|c|}{ Control } & \multirow[t]{2}{*}{ Ethnicity } & \multirow[t]{2}{*}{ Type of stone } & \multirow[t]{2}{*}{ Genotyping } & \multirow{2}{*}{$\begin{array}{l}X^{2} \\
H W E\end{array}$} & \multirow{2}{*}{$\begin{array}{l}\text { NOS [S/ } \\
\text { C/E] }\end{array}$} \\
\hline & $\mathrm{QQ}$ & QE & $\mathrm{EE}$ & $\mathrm{N}$ & $\mathrm{QQ}$ & QE & $\mathrm{EE}$ & $\mathrm{N}$ & & & & & \\
\hline Corbetta et al. 2006 [39] & 89 & 5 & 0 & 94 & 123 & 14 & 0 & 137 & Caucasian & Calcium oxalate & PCR & 0.40 & $6[3 / 1 / 2]$ \\
\hline Guha et al. 2015 [38] & 189 & 11 & 0 & 200 & 190 & 10 & 0 & 200 & Asian & Calcium oxalate & $P C R$ & 0.13 & $7[3 / 2 / 2]$ \\
\hline Li et al. 2018 [32] & 598 & 26 & 0 & 624 & 457 & 13 & 0 & 470 & Asian & Calcium oxalate & PCR & 0.09 & $8[4 / 2 / 2]$ \\
\hline Peretokina et al. 2015 [33] & 92 & 16 & 2 & 110 & 70 & 6 & 1 & 77 & Caucasian & Calcium oxalate and phosphate & PCR & 3.36 & $6[3 / 1 / 2]$ \\
\hline Shakhssalim et al. 2010 [27] & 94 & 5 & 0 & 99 & 107 & 0 & 0 & 107 & Asian & Calcium oxalate & PCR & 0.07 & $7[4 / 1 / 2]$ \\
\hline
\end{tabular}

CaSR calcium-sensing receptor, $P C R$ polymerase chain reaction, PCR-RFLP PCR-restriction fragment length polymorphism, HWE Hardy-Weinberg equilibrium, NOS Newcastle-Ottawa Scale, $S$ selection, $C$ comparability, $E$ exposure

between CaSR Q1011E gene polymorphism and the risk of urolithiasis is demonstrated in Table 6.

\section{Source of heterogeneity}

For CaSR R990G, overall, evidence for heterogeneity was observed in R and $G$ alleles and RR and RG genotypes. Therefore, random effect model was used to evaluate the correlation. For Asian sub-group, random effect model was used to assess the correlation in $\mathrm{R}$ and $\mathrm{G}$ allele and RR genotype because of heterogeneity. For Caucasian subgroup, R and G alleles and RR and RG genotypes were observed to have heterogeneity. Therefore, the correlation was assessed by random effect model. The evidence of heterogeneity for CaSR R990G is described in Table 4.

In CaSR A986S, the correlation (A vs. S; S vs. A; AA vs. AS + SS; AS vs. AA + SS) was assessed using random effect model because evidence for heterogeneity was found. On the other hand, in Asian sub-group, A and S alleles were evaluated using fixed effect model because of no heterogeneity existed, and RR and RG genotypes were assessed using random effect model because of heterogeneity. Other evidences for heterogeneity for CaSR A986S are presented in Table 5.

For CaSR Q1011E, the association and effect estimation in overall analysis and in Asian sub-group analysis were assessed using fixed effect model because of no evidence for heterogeneity. Furthermore, because the heterogeneity in Caucasian sub-group was observed, the association was evaluated using random effect model. We summarize the evidence for heterogeneity of CaSR Q1011E in Table 6.

\section{Potential publication bias}

To assess the potency of publication bias among all included papers, we used an Egger's test. For CaSR R990G (Fig. 4a), our analysis found that publication bias was observed in GG genotype both in overall analysis and Caucasian sub-group. For CaSR A986S (Fig. 4b), we found publication bias in SS genotype in both overall analysis and in Asian sub-group and AS genotype of Caucasian sub-group. Moreover, for CaSR Q1011E, publication bias was found in EE genotype of overall analysis and Caucasian sub-group. The summary of publication bias is described in Table 4 for CaSR R990G, Table 5 for CaSR A986S, and Table 6 for CaSR Q1011E.

\section{Discussion}

Our searching strategy identified eight papers evaluating the association between CaSR R990G gene polymorphism and the risk of urolithiasis. Of those, four papers [26-29] showed that R990G gene polymorphism was associated with the risk of urolithiasis with variable odd ratio, ranging from 1.24 to 8.07 ( $G$ vs. R). On the other hand, four other studies [30-33] failed to confirm the correlation. Our pooled calculation revealed that $\mathrm{R}$ allele and $\mathrm{R} R$ genotype were associated with decreased risk of urolithiasis. On the other hand, G allele and RG genotype had a significant association with increased risk of urolithiasis (Fig. 2a, b). Theoretically, the precise role of CaSR R990G in the development of urolithiasis remains undefined. However, a study in human embryonic renal cells (HEK293) revealed that G allele of CaSR R990G might activate phospholipase A or C to a different degree and escalate the function of CaSR, and therefore it was associated with increased calcium excretion [28]. On the other hand, G allele was associated with hypercalciuria in subjects without kidney stones [14]. This demonstrates that $\mathrm{G}$ allele may be associated with idiopathic hypercalciuria. Moreover, another hypothesis revealed that $\mathrm{G}$ allele was associated with increasing CaSR sensitivity to calcium, and therefore it may cause decreased calcium reabsorption in the ascending limb [34, 35]. G allele of CaSR R990G means that the basic amino acid arginine is replaced by the neutral amino acid glycine. This replacement may affect conformation and folding of receptor domains, and cause the turning of CaSR capability to activate G-proteins and to bind filamin-A. This circumstance is believed to contribute for increasing CaSR sensitivity to calcium [36]. Furthermore, a gene-gene interaction theory may also support our results. A study found that $G$ allele of CaSR R990G was reported to correlate with minor allele of rs6776158, and it was associated with reduced transcriptional activity of the CaSR gene promoter 1 . In addition, 


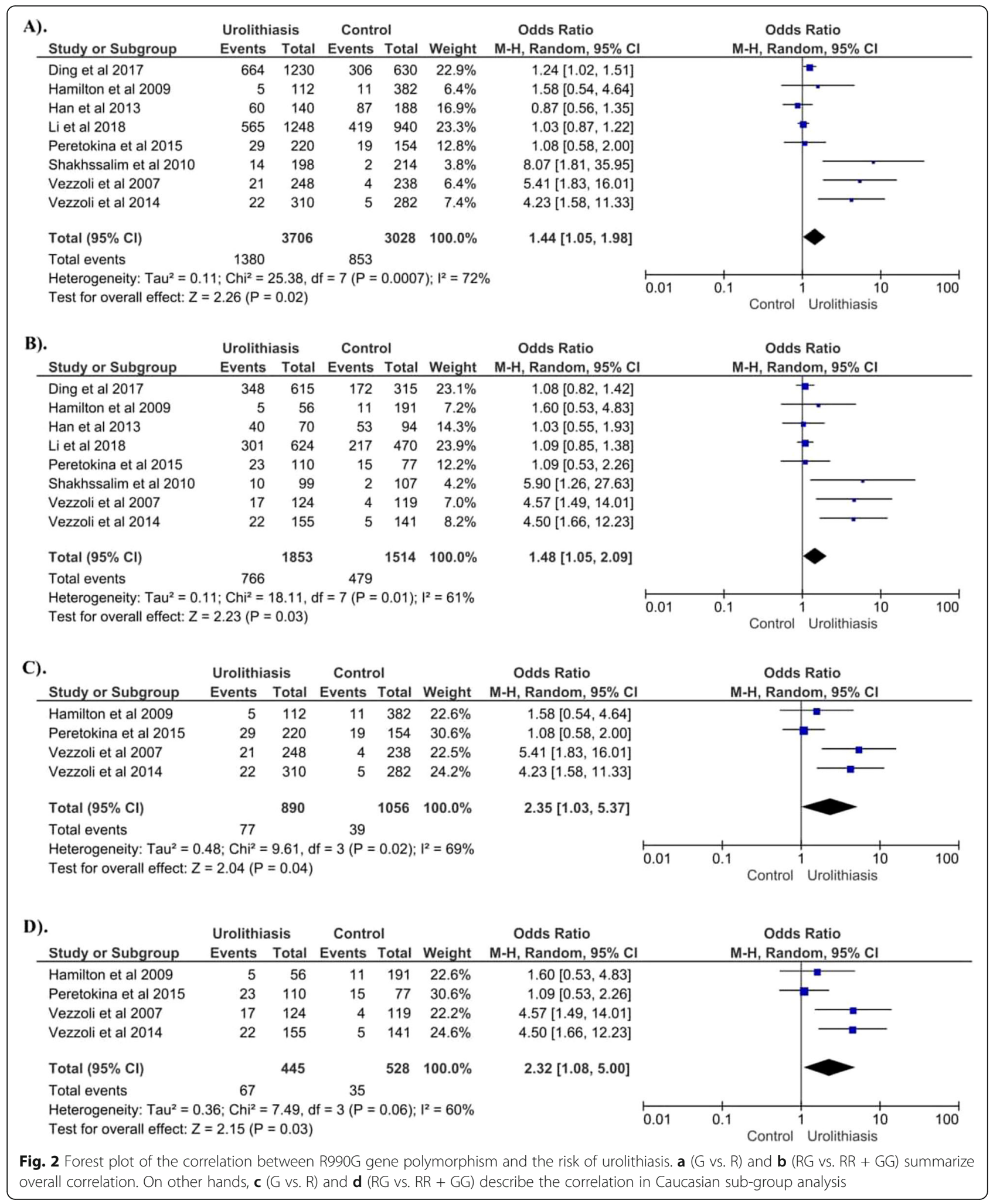

this circumstance was associated with increased risk of calcium stone formation [37]. This explanation may be a benchmark for our results showing that $G$ allele of R990G was associated with increased risk of urolithiasis. However, further studies are required to elucidate the precise mechanism how CaSR R990G affects urolithiasis.

Beside CaSR R990G, the development of urolithiasis may be also governed by CaSR A986S. Concerning the 
Table 4 Summay of the association between R990G gene polymorphism and the risk of urolithiasis

\begin{tabular}{|c|c|c|c|c|c|c|c|c|c|c|c|}
\hline \multirow{2}{*}{$\begin{array}{l}\text { Allele and } \\
\text { genotype }\end{array}$} & \multirow[t]{2}{*}{ NS } & \multirow[t]{2}{*}{ Model } & \multicolumn{2}{|l|}{ Value } & \multirow{2}{*}{$\begin{array}{l}\text { Sensitivity } \\
(\%)\end{array}$} & \multirow{2}{*}{$\begin{array}{l}\text { Specificity } \\
(\%)\end{array}$} & \multirow[t]{2}{*}{ OR } & \multirow[t]{2}{*}{$95 \% \mathrm{Cl}$} & \multirow[t]{2}{*}{$\mathrm{pH}$} & \multirow[t]{2}{*}{$\mathrm{pE}$} & \multirow[t]{2}{*}{$p$} \\
\hline & & & Case (\%) & Control (\%) & & & & & & & \\
\hline \multicolumn{12}{|l|}{ Overall analysis } \\
\hline R vs. G & 8 & Random & 62.76 & 71.83 & 62.76 & 28.17 & 0.69 & $0.51-0.95$ & 0.0010 & 0.3230 & 0.0240 \\
\hline G vs. R & 8 & Random & 37.24 & 28.17 & 37.24 & 71.83 & 1.44 & $1.05-1.98$ & 0.0010 & 0.3230 & 0.0240 \\
\hline RR vs. $R G+G G$ & 8 & Random & 42.09 & 56.01 & 42.09 & 43.99 & 0.60 & $0.41-0.89$ & 0.0040 & 0.4150 & 0.0120 \\
\hline RG vs. RR + GG & 8 & Random & 41.34 & 31.64 & 41.34 & 68.36 & 1.48 & $1.05-2.09$ & 0.0120 & 0.3360 & 0.0260 \\
\hline GG vs. RR + RG & 8 & Fixed & 16.57 & 12.35 & 16.57 & 87.65 & 1.09 & $0.89-1.35$ & 0.5240 & $<0.0001$ & 0.3950 \\
\hline \multicolumn{12}{|l|}{ Asian sub-group } \\
\hline R vs. G & 4 & Random & 53.73 & 58.72 & 53.73 & 41.28 & 0.88 & $0.66-1.17$ & 0.0180 & 0.2190 & 0.3680 \\
\hline G vs. R & 4 & Random & 46.27 & 41.28 & 46.27 & 58.72 & 1.14 & $0.86-1.52$ & 0.0180 & 0.2190 & 0.3680 \\
\hline RR vs. $R G+G G$ & 4 & Random & 28.91 & 36.21 & 28.91 & 63.79 & 0.77 & $0.51-1.16$ & 0.0400 & 0.3050 & 0.2090 \\
\hline $\mathrm{RG}$ vs. RR + GG & 4 & Fixed & 49.64 & 45.03 & 49.64 & 54.97 & 1.10 & $0.93-1.31$ & 0.2030 & 0.1470 & 0.2600 \\
\hline GG vs. RR + RG & 4 & Fixed & 21.45 & 18.76 & 21.45 & 81.24 & 1.09 & $0.88-1.34$ & 0.4350 & 0.3550 & 0.0710 \\
\hline \multicolumn{12}{|c|}{ Caucasian sub-group } \\
\hline R vs. G & 4 & Random & 91.35 & 96.31 & 91.35 & 3.69 & 0.43 & $0.19-0.96$ & 0.0240 & 0.6820 & 0.0400 \\
\hline G vs. R & 4 & Random & 8.65 & 3.69 & 8.65 & 96.31 & 2.35 & $1.03-5.37$ & 0.0240 & 0.6820 & 0.0400 \\
\hline RR vs. RG + GG & 4 & Random & 83.82 & 92.99 & 83.82 & 7.01 & 0.42 & $0.19-0.93$ & 0.0380 & 0.6540 & 0.0330 \\
\hline RG vs. RR + GG & 4 & Random & 15.06 & 6.63 & 15.06 & 93.37 & 2.32 & $1.08-5.00$ & 0.0600 & 0.5980 & 0.0310 \\
\hline$G G$ vs. RR + RG & 4 & Fixed & 1.12 & 0.38 & 1.12 & 99.62 & 1.57 & $0.33-7.46$ & 0.3960 & $<0.0001$ & 0.5700 \\
\hline
\end{tabular}

NS number of studies, $O R$ odd ratio, $\mathrm{Cl}$ confidence interval, $\mathrm{pH} \mathrm{p}$ heterogeneity, $\mathrm{pE} \mathrm{p}$ egger

correlation between CaSR A986S gene polymorphism and the risk of urolithiasis, of nine papers, our results found that three papers $[27,30,38]$ showed the correlation, and six others $[26,31-33,39,40]$ failed to show the association. Of those, the odd ratio ranged from 1.96 to 2.55 (S vs. A). Our combination data demonstrated that A allele and AA genotype were correlated with decreased risk of urolithiasis. Conversely, $\mathrm{S}$ allele was associated with increased risk of urolithiasis (Fig. 3a). To date, the perspective theory underlying our results was lacking. However, several studies had reported that increased CaSR activity was observed in S allele of CaSR A986S gene polymorphism [18]. Moreover, S allele of CaSR A986S was also reported to be associated with the decrease of inhibitory activity of CaSR on tubular calcium reabsorption [28]. Therefore, it may govern calcium homeostasis. Furthermore, S allele of CaSR A986S gene polymorphism had been widely reported to affect elevated level of calcium concentration [41, 42]. Those reports might be the basis explaining the results of our study. Nevertheless, the proper mechanism concerning the role of CaSR A986S in patients with urolithiasis needs to be further investigated.

Moreover, because the pathogenesis of urolithiasis is complex and may involve specific interactions including gene-gene and/or gene-environment interaction, this pathogenesis may implicate other SNPs such as CaSR Q1011E. For this reason, we also evaluated the role of
CaSR Q1011E gene polymorphism in patients with urolithiasis. Although Q allele was reported to be associated with elevated calcium concentration and hypercalciuric state [27], and previous meta-analysis also confirmed that CaSR Q1011E gene polymorphism was associated with urolithiasis in specific population [18]; however, of five papers we collected [27, 32, 33, 38, 39], all of them failed to show the association. Our pooled calculation also revealed that no association was found in all genetic models between CaSR Q1011E gene polymorphism and the risk of urolithiasis. In sub-group analysis, we also failed to clarify the association.

A previous study [18] had reported the meta-analysis concerning this topic. Overall, our results were consistent with this previous study. However, we found some limitations in the previous study, such as relatively small sample size, data discrepancy, data duplication, and deviation from Hardy-Weinberg equilibrium. Compared to previous study, our current study had larger sample size. Their meta-analysis only involved seven papers for CaSR R990G, six papers for CaSR A986S, and three papers for CaSR Q1011E. Meanwhile, our present study involved eight papers for CaSR R990G, nine papers for CaSR A986S, and five papers for CaSR Q1011E. This comparison might demonstrate that, because of having larger sample size, our present study might have better statistical power to explore the real association. Moreover, we also found irrelevant data or data discrepancy between 


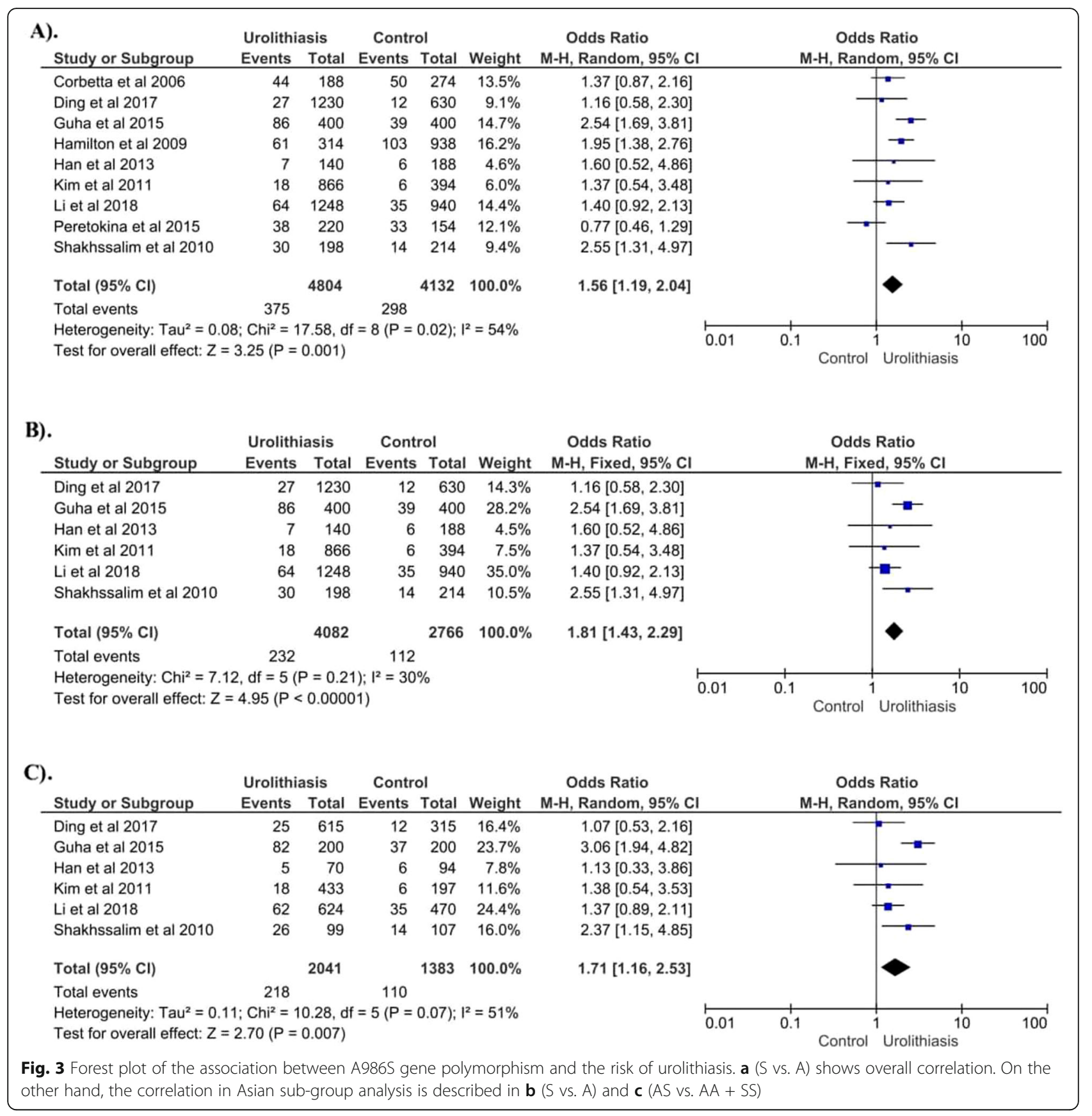

data presented in the meta-analysis and data in the original paper. Data discrepancy often occurs in data analysis using large sample size without checking for validity. To prevent data discrepancy, data extraction and analysis in our present study were performed by three independent authors. Furthermore, HardyWeinberg deviation was also found in the previous study. In the genetic population, Hardy-Weinberg equilibrium is the basic principle of genetic and considered as one of the most important principles in population of genetics. This principle has been universally employed for the study of allele and genotype frequency changes in a population over generations [43]. In the context of deviation from this principle, it had been demonstrated that whatever method was used if Hardy-Weinberg equilibrium was not established, they might result in nothing [44]. Therefore, because of those several limitations, our present meta-analysis might clarify better correlation between CaSR gene polymorphisms and the risk of urolithiasis.

In sub-group analysis, interestingly, our findings revealed that the correlation between CaSR R990G gene 
Table 5 Summary of the correlation between A986S gene polymorphism and the risk of urolithiasis

\begin{tabular}{|c|c|c|c|c|c|c|c|c|c|c|c|}
\hline \multirow{2}{*}{$\begin{array}{l}\text { Allele and } \\
\text { genotype }\end{array}$} & \multirow[t]{2}{*}{ NS } & \multirow[t]{2}{*}{ Model } & \multicolumn{2}{|l|}{ Value } & \multirow{2}{*}{$\begin{array}{l}\text { Sensitivity } \\
(\%)\end{array}$} & \multirow{2}{*}{$\begin{array}{l}\text { Specificity } \\
(\%)\end{array}$} & \multirow[t]{2}{*}{ OR } & \multirow[t]{2}{*}{$95 \% \mathrm{Cl}$} & \multirow[t]{2}{*}{$\mathrm{pH}$} & \multirow[t]{2}{*}{$\mathrm{pE}$} & \multirow[t]{2}{*}{$p$} \\
\hline & & & Case (\%) & Control (\%) & & & & & & & \\
\hline \multicolumn{12}{|l|}{ Overall analysis } \\
\hline A vs. S & 9 & Random & 92.19 & 92.79 & 92.19 & 7.21 & 0.64 & $0.49-0.84$ & 0.0250 & 0.2910 & 0.0010 \\
\hline S vs. A & 9 & Random & 7.81 & 7.21 & 7.81 & 92.79 & 1.56 & $1.19-2.04$ & 0.0250 & 0.2910 & 0.0010 \\
\hline$A A$ vs. AS + SS & 9 & Random & 85.85 & 86.30 & 85.85 & 13.70 & 0.66 & $0.48-0.91$ & 0.0110 & 0.3580 & 0.0110 \\
\hline$A S$ vs. $A A+S S$ & 9 & Random & 12.70 & 12.97 & 12.70 & 87.03 & 1.34 & $0.95-1.88$ & 0.0040 & 0.4070 & 0.0990 \\
\hline SS vs. AA + AS & 9 & Fixed & 1.46 & 0.73 & 1.46 & 99.27 & 3.34 & $1.85-6.02$ & 0.5040 & $<0.0001$ & $<0.0001$ \\
\hline \multicolumn{12}{|l|}{ Asian sub-group } \\
\hline A vs. S & 6 & Fixed & 94.32 & 95.95 & 94.32 & 4.05 & 0.55 & $0.44-0.70$ & 0.2120 & 0.2020 & $<0.0001$ \\
\hline S vs. A & 6 & Fixed & 5.68 & 4.05 & 5.68 & 95.95 & 1.81 & $1.43-2.29$ & 0.2120 & 0.2020 & $<0.0001$ \\
\hline$A A$ vs. $A S+S S$ & 6 & Random & 88.98 & 91.97 & 88.98 & 8.03 & 0.56 & $0.38-0.82$ & 0.0710 & 0.3300 & 0.0030 \\
\hline$A S$ vs. $A A+S S$ & 6 & Random & 10.68 & 7.95 & 10.68 & 92.05 & 1.71 & $1.16-2.53$ & 0.0680 & 0.3370 & 0.0070 \\
\hline SS vs. AA + AS & 6 & Fixed & 0.34 & 0.07 & 0.34 & 99.93 & 2.67 & $0.71-10.03$ & 0.9770 & $<0.0001$ & 0.1450 \\
\hline \multicolumn{12}{|c|}{ Caucasian sub-group } \\
\hline A vs. S & 3 & Random & 80.19 & 86.38 & 80.19 & 13.62 & 0.77 & $0.45-1.30$ & 0.0130 & 0.4070 & 0.3200 \\
\hline S vs. A & 3 & Random & 19.81 & 13.62 & 19.81 & 86.38 & 1.31 & $0.77-2.21$ & 0.0130 & 0.4070 & 0.3200 \\
\hline AA vs. AS + SS & 3 & Random & 68.14 & 74.82 & 68.14 & 25.18 & 0.86 & $0.53-1.42$ & 0.0660 & 0.3470 & 0.5630 \\
\hline AS vs. AA + SS & 3 & Fixed & 24.10 & 23.13 & 24.10 & 76.87 & 0.94 & $0.69-1.28$ & 0.4030 & $<0.0001$ & 0.6840 \\
\hline SS vs. AA + AS & 3 & Random & 7.76 & 2.05 & 7.76 & 97.95 & 3.10 & $1.00-9.64$ & 0.0570 & 0.8070 & 0.0510 \\
\hline
\end{tabular}

NS number of studies, $O R$ odd ratio, $\mathrm{Cl}$ confidence interval, $\mathrm{pH} \mathrm{p}$ heterogeneity, $\mathrm{pE} \mathrm{p}$ egger

Table 6 Summary of the association between Q1011E gene polymorphism and the risk of urolithiasis

\begin{tabular}{|c|c|c|c|c|c|c|c|c|c|c|c|}
\hline \multirow{2}{*}{$\begin{array}{l}\text { Allele and } \\
\text { genotype }\end{array}$} & \multirow[t]{2}{*}{ NS } & \multirow[t]{2}{*}{ Model } & \multicolumn{2}{|l|}{ Value } & \multirow{2}{*}{$\begin{array}{l}\text { Sensitivity } \\
\text { (\%) }\end{array}$} & \multirow{2}{*}{$\begin{array}{l}\text { Specificity } \\
(\%)\end{array}$} & \multirow[t]{2}{*}{ OR } & \multirow[t]{2}{*}{$95 \% \mathrm{Cl}$} & \multirow[t]{2}{*}{$\mathrm{pH}$} & \multirow[t]{2}{*}{$\mathrm{pE}$} & \multirow[t]{2}{*}{$\mathrm{p}$} \\
\hline & & & Case (\%) & Control (\%) & & & & & & & \\
\hline \multicolumn{12}{|l|}{ Overall analysis } \\
\hline Q vs. E & 5 & Fixed & 97.03 & 97.73 & 97.03 & 2.27 & 0.77 & $0.51-1.16$ & 0.1710 & 0.3770 & 0.2110 \\
\hline E vs. Q & 5 & Fixed & 2.97 & 2.27 & 2.97 & 97.73 & 1.30 & $0.86-1.95$ & 0.1710 & 0.3770 & 0.2110 \\
\hline $\mathrm{QQ}$ vs. QE + EE & 5 & Fixed & 94.23 & 95.56 & 94.23 & 4.44 & 0.77 & $0.50-1.17$ & 0.1560 & 0.4090 & 0.2150 \\
\hline QE vs. QQ + EE & 5 & Fixed & 5.59 & 4.34 & 5.59 & 95.66 & 1.30 & $0.85-2.00$ & 0.1550 & 0.4160 & 0.2290 \\
\hline EE vs. QQ + QE & 5 & Fixed & 0.18 & 0.10 & 0.18 & 99.90 & 1.41 & $0.13-15.80$ & 0.7820 & 1.0000 & $<0.0001$ \\
\hline \multicolumn{12}{|l|}{ Asian sub-group } \\
\hline Q vs. E & 3 & Fixed & 97.72 & 98.52 & 97.72 & 1.48 & 0.69 & $0.41-1.17$ & 0.2910 & 0.2580 & 0.1660 \\
\hline E vs. Q & 3 & Fixed & 2.28 & 1.48 & 2.28 & 98.52 & 1.45 & $0.86-2.44$ & 0.2910 & 0.2580 & 0.1660 \\
\hline $\mathrm{QQ}$ vs. QE + EE & 3 & Fixed & 94.45 & 97.04 & 94.45 & 2.96 & 0.69 & $0.41-1.16$ & 0.2870 & 0.2680 & 0.1610 \\
\hline QE vs. QQ + EE & 3 & Fixed & 4.55 & 2.96 & 4.55 & 97.04 & 1.46 & $0.86-2.47$ & 0.2870 & 0.2680 & 0.1610 \\
\hline EE vs. QQ + QE & 3 & NA & 0.00 & 0.00 & 0.00 & 100.00 & NA & NA & NA & NA & NA \\
\hline \multicolumn{12}{|c|}{ Caucasian sub-group } \\
\hline Q vs. E & 2 & Random & 93.87 & 94.86 & 93.87 & 5.14 & 1.00 & $0.29-3.51$ & 0.0610 & 0.7650 & 0.9980 \\
\hline E vs. Q & 2 & Random & 6.13 & 5.14 & 6.13 & 94.86 & 1.00 & $0.29-3.49$ & 0.0610 & 0.7650 & 0.9980 \\
\hline $\mathrm{QQ}$ vs. QE + EE & 2 & Random & 88.73 & 90.19 & 88.73 & 9.81 & 0.99 & $0.26-3.83$ & 0.0550 & 0.8310 & 0.9920 \\
\hline QE vs. QQ + EE & 2 & Random & 10.29 & 9.35 & 10.29 & 90.65 & 1.01 & $0.26-4.01$ & 0.0570 & 0.8460 & 0.9880 \\
\hline EE vs. QQ + QE & 2 & Fixed & 0.98 & 0.47 & 0.98 & 99.53 & 1.41 & $0.13-15.80$ & 1.0000 & $<0.0001$ & 0.7820 \\
\hline
\end{tabular}


A).

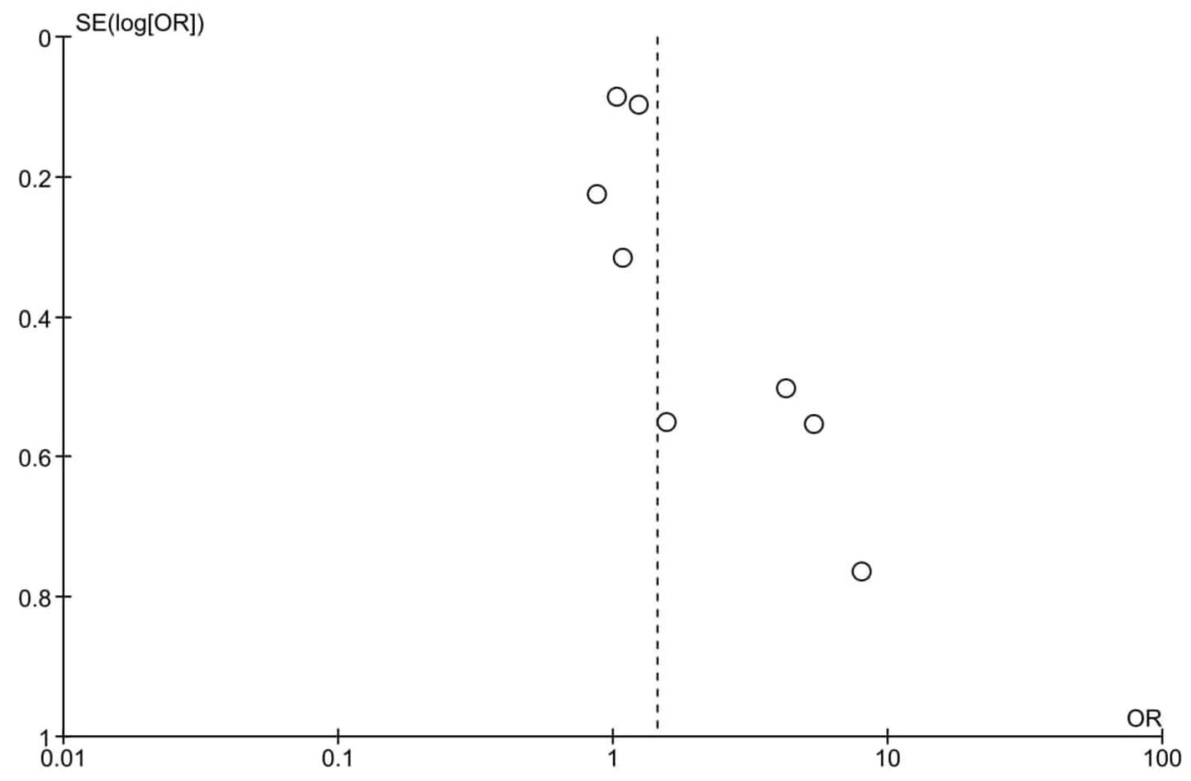

B).

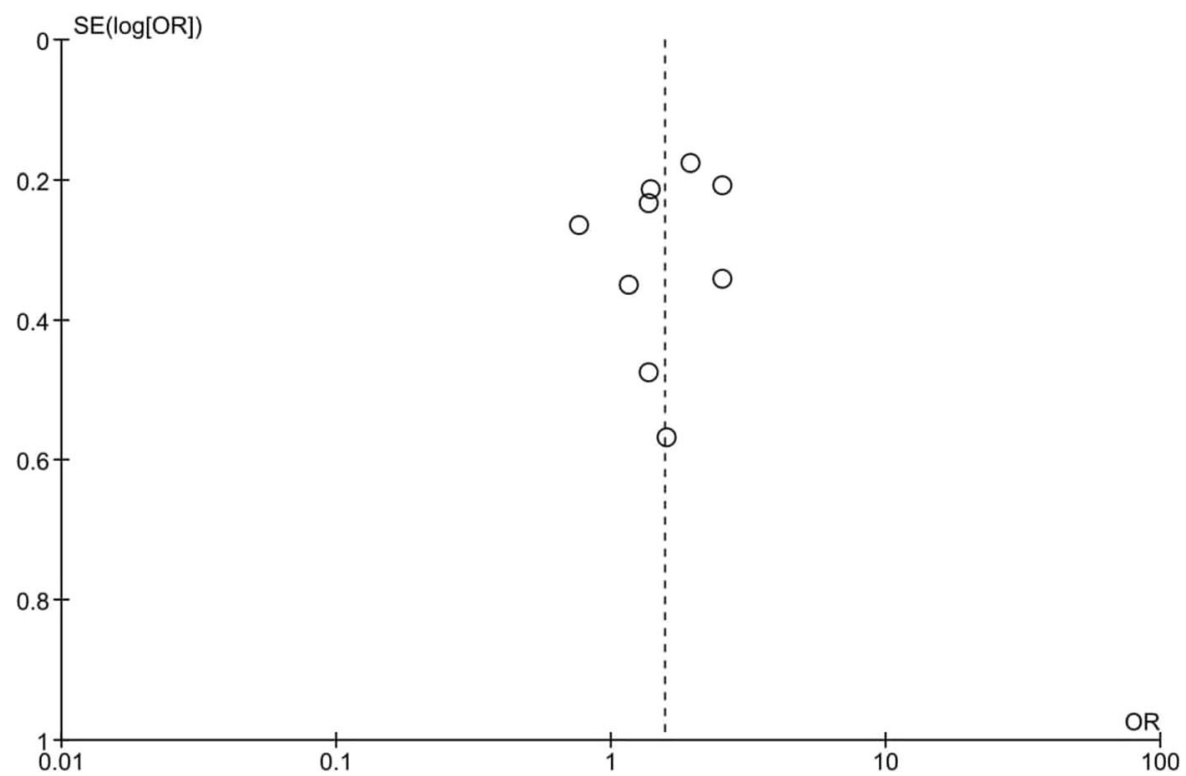

Fig. 4 Funnel plot of the association between the risk of urilithiasis and (a) R990G and (b) A986S gene polymorphisms

polymorphism and the risk of urolithiasis was observed in Caucasian population (Fig. 2c, d). Moreover, in Asian population, the correlation was found in CaSR A986S (Fig. 3b, c). Our results might demonstrate gene-environment interaction. It attests that CaSR R990G has a dominant role in Caucasian, and CaSR A986S is dominant in Asian. The mechanism underlying our resultsrelated ethnicity is not well known. Although the correlation perspective has widely proposed that "where there is sugar, there are bound to be ants,"because of the lack of evidence concerning this report, our results-related ethnicity were difficult to explain. However, genetic background and gene-environment interaction may play a crucial role in this circumstance. Until now, no study reports the exact explanation concerning CaSR gene polymorphisms in the context of ethnicity. Therefore, in the near future, we expect that this puzzle may be elucidated.

Although we provided the evidence that the risk of urolithiasis was associated with CaSR R990G and CaSR 
A986S gene polymorphisms, however, at present time, it was not possible to use these SNPs as biomarkers or predictors of urolithiasis. Our results might clarify the controversy during this time and confirm better understanding concerning the role of these SNPs in patients with urolithiasis. Moreover, since the reported studies used non-randomized design, it might result in a lowlevel of evidence. Therefore, further studies with a higher design may be required.

Several crucial limitations were observed in our present study. First, several factors having pivotal role in the pathogenesis and development of urolithiasis such as age, dietary, hyperparathyroidism, previous urolithiasis, and family history of urolithiasis [45] were not controlled for and included in our study. Second, the findings of our study should be interpreted with caution because of relatively small sample size in both overall analysis and sub-group analysis. Third, unequal proportion of papers included in our analysis in each subgroup was observed, and therefore, this factor may lead to heterogeneity and study bias. Fourth, most of study design in our database was cross-sectional. Further meta-analysis including better study designs may be needed to achieve a higher level of evidence. Because of the limitations, further studies eliminating these factors may be required to elucidate the better correlation between the risk of urolithiasis and the CaSR gene polymorphisms.

\section{Conclusions}

Our study reveals that $\mathrm{R}$ allele and RR genotype of CaSR R990G and A allele and AA genotype of CaSR A986S gene polymorphisms are asociated with protective effect againsts urolithiasis. On the other hand, G allele and RG genotype of CaSR R990G and S allele of CaSR A986S gene polymorphisms are correlated with increased risk of urolithiasis. In sub-group analysis, the correlation in Caucasian population is observed in CaSR R990G, while the association in CaSR A986S is found in Asian population. Our results may clarify better correlation concerning gene-disease interaction between CaSR gene polymorphisms and the risk of urolithiasis.

\footnotetext{
Abbreviations

95\%Cl: 95\% confidence interval; A986S: A guanine-thymine substitution at codon 986; CaSR: Calcium-sensing receptor; CMA: Comprehensive metaanalysis; GPCR: G-protein coupled receptor; HEK293: Human embryonic renal cells; HWE: Hardy-Weinberg equilibrium; NOS: Newcastle-Ottawa Scale; OR: Odd ratio; PRISMA: Preferred Reporting Items for Systematic Review and Meta-analysis; Q1011E: A cytosine-guanine substitution at codon 1011; R990G: The subtitution of an adenine - guanine at codon 990; Revman: Review manager; SNPs: Single-nucleotide polymorphisms
}

\section{Authors' contributions}

Idea/concept: BD; BBP; AG. Design: BD; BBP; AG. Control/supervision: BD; BBP. AG. Data collection/processing: BD; BBP; AG; FT; SAH; EDM; AGK; JKF. Extraction/Analysis/interpretation: AG; FT; JKF. Literature review: BD; BBP; $A G$; JKF. Writing the article: JKF. Critical review: BD; BBP; AG. All authors have critically reviewed and approved the final draft and are responsible for the content and similarity index of the manuscript.

\section{Funding}

Not applicable.

\section{Availability of data and materials}

Data used in our study were presented in the main text.

Ethics approval and consent to participate

Not applicable.

\section{Consent for publication}

Not applicable.

\section{Competing interests}

Not applicable.

\section{Author details}

${ }^{1}$ Department of Urology, Faculty of Medicine, Universitas Brawijaya, Malang 65145 , Indonesia. ${ }^{2}$ Division of Nephrology and Hypertension, Department of Internal Medicine, Faculty of Medicine, Universitas Brawijaya, Malang 65145, Indonesia. ${ }^{3}$ Brawijaya Internal Medicine Research Center, Department of Internal Medicine, Faculty of Medicine, Universitas Brawijaya, Malang 65145, Indonesia. ${ }^{4}$ Faculty of Medicine, Universitas Brawijaya, Malang 65145, Indonesia. ${ }^{5}$ Medical Research Unit, School of Medicine, Universitas Syiah Kuala, Banda Aceh 23111, Indonesia.

Received: 24 September 2019 Accepted: 23 December 2019

Published online: 31 December 2019

\section{References}

1. Lu YM, Chien TM, Li CC, Chou YH, Wu WJ, Huang CN. Urolithiasis is associated with the increased risk for osteoporosis: A nationwide 9-year follow-up study. Urological Sci 2017. https://doi.org/10.1016/j.urols.2017.07. 010.

2. Lee YH, Huang WC, Tsai JY, Lu CM, Chen WC, Lee MH, Hsu HS, Huang JK, Chang LS (2002) Epidemiological studies on the prevalence of upper urinary calculi in Taiwan. Urol Int 68(3):172-177

3. Hesse A, Brändle E, Wilbert D, Köhrmann KU, Alken P. Study on the prevalence and incidence of urolithiasis in Germany comparing the years 1979 vs. 2000 Eur Urol 2003; 44(6): 709 - 713.

4. Stamatelou KK, Francis ME, Jones CA, Nyberg LM, Curhan GC (2003) Time trends in reported prevalence of kidney stones in the United States: 19761994. Kidney Int 63(5):1817-1823

5. Lieske JC, de la Vega LS P, Slezak JM, Bergstralh EJ, Leibson CL, Ho KL, Gettman MT (2006) Renal stone epidemiology in Rochester, Minnesota: an update. Kidney Int 69(4):760-764

6. Stamatiou KN, Karanasiou VI, Lacroix RE, Kavouras NG, Papadimitriou VT, Chlopsios C, Lebren FA, Sofras F (2006) Prevalence of urolithiasis in rural Thebes. Greece. Rural Remote Health 6(4):610

7. Indridason OS, Birgisson S, Edvardsson VO, Sigvaldason H, Sigfusson N, Palsson R (2006) Epidemiology of kidney stones in Iceland: a populationbased study. Scand J Urol Nephrol 40(3):215-220

8. Safarinejad MR (2007) Adult urolithiasis in a population-based study in Iran: prevalence, incidence, and associated risk factors. Urol Res 35(2):73-82

9. Joual A, Fekak H, Rabii R, el Moussasoui A, Benjelloun S (1996) Complications of urinary calculi. Ann Urol (Paris) 30(5):251-256

10. Alelign T, Petros B (2018) Kidney Stone Disease: An Update on Current Concepts. Adv Urol 2018:3068365

11. Shafi H, Moazzami B, Pourghasem M, Kasaeian A (2016) An overview of treatment options for urinary stones. Caspian J Intern Med 7(1):1-6

12. Strohmaier WL (2012) Economics of stone disease/treatment. Arab J Urol 10(3):273-278

13. Craven BL, Passman C, Assimos DG (2008) Hypercalcemic states associated with nephrolithiasis. Rev Urol 10(3):218-226 
14. Vezzoli G, Terranegra A, Rainone F, Arcidiacono T, Cozzolino M, Aloia A, Dogliotti E, Cusi D, Soldati L (2011) Calcium-sensing receptor and calcium kidney stones. J Transl Med 9:201

15. Brown EM, Gamba G, Riccardi D, Lombardi M, Butters R, Kifor O, Sun A, Hediger MA, Lytton J, Hebert SC (1993) Cloning and characterization of an extracellular $\mathrm{Ca}(2+)$-sensing receptor from bovine parathyroid. Nature 366(6455):575-580

16. Canaff L, Hendy GN (2002) Human calcium-sensing receptor gene. Vitamin $D$ response elements in promoters $\mathrm{P} 1$ and $\mathrm{P} 2$ confer transcriptional responsiveness to 1,25-dihydroxyvitamin D. J Biol Chem 277(33):3033730350

17. Yamauchi M, Sugimoto T, Yamaguchi T, Yano S, Kanzawa M, Kobayashi A, Chihara K (2001) Association of polymorphic alleles of the calcium-sensing receptor gene with the clinical severity of primary hyperparathyroidism. Clin Endocrinol (Oxf) 55(3):373-379

18. Liu K, Wang X, Ye J, Qin C, Shao P, Zhang W, Li J, Yin C (2015) The G allele of CaSR R990G polymorphism increases susceptibility to urolithiasis and hypercalciuria: evidences from a comprehensive meta-analysis. Biomed Res Int 2015:958207

19. Fajar JK, Azharuddin A. The association between interleukin $6-174 \mathrm{G} / \mathrm{C}$ gene polymorphism and the risk of osteoporosis: A meta-analysis. J Taibah University Med Sci 2017; 12(3): 212-220.

20. Fajar JK, Heriansyah T, Rohman MS (2018) The predictors of no reflow phenomenon after percutaneous coronary intervention in patients with ST elevation myocardial infarction: A meta-analysis. Indian Heart J 70(Suppl 3): S406-S418

21. Fajar JK, Mahendra Al, Tamara F, Mahdi BA, Heriansyah T, Rohman MS (2019) The Association Between Complete Blood Count and the Risk of Coronary Heart Disease. Turkiye Klinikleri J Med Sci 39(1):56-64

22. Rohman MS, Fajar JK, Kuncahyo BH, Yunita L, Sidarta EP, Saka PNB, Heriansyah T, Widodo N (2018) Angiotensin-converting enzyme (ACE) I/D and bradykinin $\mathrm{B} 2$ receptor $\mathrm{T} / \mathrm{C}$ genes polymorphism in patients with $\mathrm{ACE}$ inhibitors-related cough. Egypt J Med Hum Genet 19(4):307-313

23. Moher D, Liberati A, Tetzlaff J (2009) Altman DG; PRISMA Group. Preferred reporting items for systematic reviews and meta-analyses: the PRISMA statement. Ann Intern Med 151(4):264-269

24. Rodriguez S, Gaunt TR, Day IN (2009) Hardy-Weinberg equilibrium testing of biological ascertainment for Mendelian randomization studies. Am Epidemiol 169(4):505-514

25. Bae JM (2016) A suggestion for quality assessment in systematic reviews of observational studies in nutritional epidemiology. Epidemiol Health 38 : e2016014

26. Ding Q, Fan B, Shi Y, Fan Z, Ding L, Li F, Tu W, Jin X, Qin C, Cao Q, Yuan Q, Wang J, Ouyang J (2017) Calcium-sensing receptor genetic polymorphisms and risk of developing nephrolithiasis in a Chinese population. Urol Int 99(3):331-337

27. Shakhssalim N, Kazemi B, Basiri A, Houshmand M, Pakmanesh H, Golestan B, Eilanjegh AF, Kashi AH, Kilani M, Azadvari M (2010) Association between calcium-sensing receptor gene polymorphisms and recurrent calcium kidney stone disease: a comprehensive gene analysis. Scand J Urol Nephrol 44(6):406-412

28. Vezzoli G, Terranegra A, Arcidiacono T, Biasion R, Coviello D, Syren ML, Paloschi V, Giannini S, Mignogna G, Rubinacci A, Ferraretto A, Cusi D, Bianchi G, Soldati L (2007) R990G polymorphism of calcium-sensing receptor does produce a gain-of-function and predispose to primary hypercalciuria. Kidney Int 71(11):1155-1162

29. Vezzoli G, Scillitani A, Corbetta S, Terranegra A, Dogliotti E, Guarnieri V, Arcidiacono T, Macrina L, Mingione A, Brasacchio C, Eller-Vainicher C, Cusi D, Spada A, Cole DE, Hendy GN, Spotti D, Soldati L (2014) Risk of nephrolithiasis in primary hyperparathyroidism is associated with two polymorphisms of the calcium-sensing receptor gene. J Nephrol 28(1):67-72

30. Hamilton DC, Grover VK, Smith CA, Cole DE (2009) Heterogeneous disease modeling for Hardy-Weinberg disequilibrium in case-control studies: application to renal stones and calcium-sensing receptor polymorphisms. Ann Hum Genet 73(2):176-183

31. Han G, Wang O, Nie M, Zhu Y, Meng X, Hu Y, Liu H, Xing X (2013) Clinical phenotypes of Chinese primary hyperparathyroidism patients are associated with the calcium-sensing receptor gene R990G polymorphism. Eur J Endocrinol 169(5):629-638

32. Li H, Zhang J, Long J, Shi J, Luo Y (2018) Calcium-sensing receptor gene polymorphism (rs7652589) is associated with calcium nephrolithiasis in the population of Yi nationality in Southwestern China. Ann Hum Genet 82(5): 265-271

33. Peretokina EV, Pigarova EA, Mokrysheva NG, Rozhinskaya LY, Baydakova GV, Zakharova EY (2015) Analysis of the association of polymorphisms CASR and VDR with the development of nephrolithiasis in patients with primary hyperparathyroidism. Problems of Endocrinology 61(5):4-8

34. Yokoyama K, Shigematsu T, Tsukada T, Hara S, Yamada S, Kawaguch Y, Hosoya T (2002) Calcium-sensing receptor gene polymorphism affects the parathyroid response to moderate hypercalcemic suppression in patients with end-stage renal disease. Clinical Nephrology 57:131-135

35. Rothe HM, Shapiro WB, Sun WY, Chou S-Y (2005) Calcium-sensing receptorgene polymorphismR990Gand its possible effectonresponse to cinacalcet HCl. Pharmacogenetics and Genomics 15:29-34

36. Gama L, Breitwieser GE (1998) A carboxyl-terminal domain controls the cooperativity for extracellular Ca2+ activation of the human calcium sensing receptor. A study with receptor-green fluorescent protein fusions. J Biol Chem 273(45):29712-29718

37. Vezzoli G, Terranegra A, Aloia A, Arcidiacono T, Milanesi L, Mosca E, Mingione A, Spotti D, Cusi D, Hou J, Hendy GN, Soldati L; GENIAL network (Genetics and Environment in Nephrolithiasis Italian Alliance), Paloschi V, Dogliotti E, Brasacchio C, Dell'Antonio G, Montorsi F, Bertini R, Bellinzoni P, Guazzoni G, Borghi L, Guerra A, Allegri F, Ticinesi A, Meschi T, Nouvenne A, Lupo A, Fabris A, Gambaro G, Strazzullo P, Rendina D, De Filippo G, Brandi ML, Croppi E, Cianferotti L, Trinchieri A, Caudarella R, Cupisti A, Anglani F, Del Prete D. Decreased transcriptional activity of calcium-sensing receptor gene promoter 1 is associated with calcium nephrolithiasis. J Clin Endocrinol Metab 2013; 98(9): 3839 - 3847.

38. Guha M, Bankura B, Ghosh S, Pattanayak AK, Ghosh S, Pal DK, Puri A, Kundu AK, Das M (2015) Polymorphisms in CaSR and CLDN14 Genes associated with increased risk of kidney stone disease in patients from the Eastern Part of India. PLoS One 10(6):e0130790

39. Corbetta S, Eller-Vainicher C, Filopanti M, Saeli P, Vezzoli G, Arcidiacono T, Loli P, Syren ML, Soldati L, Beck-Peccoz P, Spada A (2006) R990G polymorphism of the calcium-sensing receptor and renal calcium excretion in patients with primary hyperparathyroidism. Eur J Endocrinol 155(5):687692

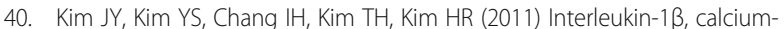
sensing receptor, and urokinase gene polymorphisms in korean patients with urolithiasis. Korean J Urol 52(5):340-344

41. Cole DE, Peltekova VD, Rubin LA, Hawker GA, Vieth R, Liew CC, Hwang DM, Evrovski J, Hendy GN (1999) A986S polymorphism of the calcium-sensing receptor and circulating calcium concentrations. Lancet 353(9147):112-115

42. He Y, Han L, Li W, Shu X, Zhao C, He Y, Bi M, Li Y, Sun C (2012) Effects of the calcium-sensing receptor A986S polymorphism on serum calcium and parathyroid hormone levels in healthy individuals: a meta-analysis. Gene 491(2):110-115

43. Wang J, Shete S (2012) Testing departure from Hardy-Weinberg proportions Methods Mol Biol 850:77-102

44. Matsuura M, Eguchi S (1990) Estimation of gene frequency and test for Hardy-Weinberg equilibrium in the HLA system. Environ Health Perspect 87: 149-155

45. O'Kell AL, Grant DC, Khan SR (2017) Pathogenesis of calcium oxalate urinary stone disease: species comparison of humans, dogs, and cats. Urolithiasis 45(4):329-336

\section{Publisher's Note}

Springer Nature remains neutral with regard to jurisdictional claims in published maps and institutional affiliations. 